\title{
Physiological and Fluorescence Reaction of Four Rice Genotypes to Exogenous Application of IAA and Kinetin under Drought Stress
}

\author{
Mostafa SALEHIFAR ${ }^{1 *}$, Babak RABIEI ${ }^{2}$, \\ Mansour AFSHAR MOHAMMADIAN ${ }^{1}$, Jafar ASGHARI ${ }^{3}$ \\ ${ }^{1}$ University of Guilan, Faculty of Science, Department of Biology, Rasht, \\ Iran; msalehifar.6262@yahoo.com (*correspondingauthor);Afshar@guilan.ac.ir \\ ${ }^{2}$ University of Guilan, Faculty of Agricultural Science, Department of Agronomy and Plant Breeding, Rasht, Iran; Rabiei@guilan.ac.ir \\ ${ }^{3}$ University of Guilan, Faculty of Agricultural Science, Department of Agronomy and Plant Breeding, Rasht, Iran; jafaghr@guilan.ac.ir
}

\begin{abstract}
To assess the effects of IAA and Kinetin plant growth regulators in order to improve the drought tolerance in rice seedlings (Oryza sativa L.), a factorial experiment was carried out based on complete randomized design with three replications. The experimental factors included different rice genotypes ['Gharib', 'Khazar', 'Sepidrood' and 'IR83750 -131-1' ('IR83750')], drought stress from 1 to 4 code of the Vergara coding system and control (normal irrigation) and growth regulators in three levels (IAA and Kinetin through foliar spraying and non-application as control). The results indicated, under normal irrigation condition together with IAA application, 'IR83750' rice genotype had the highest number of tillers and leaf greenness, with mean of 18.27 and 49.46 , respectively. The highest amount of leaf relative water content (95.11\%) was related to 'Sepidrood'. Under drought stress condition, the highest electrolyte leakage (36.59\%) was observed in 'Gharib'. In drought condition, the highest leaf drying score was related to 'Gharib' in both years, but the highest score of leaf rolling index (9) was observed in 'Gharib' and 'Khazar'. The present findings showed that drought stress had harmful effects in all examined genotypes and the impact in susceptible genotypes ('Gharib' and 'Khazar') was more than 'IR83750' and 'Sepidrood'. Application of growth regulators (IAA and Kin) improved growth conditions for of all genotypes. Therefore, using tolerant genotypes along with growth regulators can improve the rice growth traits.
\end{abstract}

Keywords: fluorescence, leaf rolling index, plant growth regulator, relative water content

\section{Introduction}

Abiotic stresses, such as drought and salinity are primary factors that limit crop and rice production (Farooq et al., 2009). Increasing environmental stresses (drought and salinity) to 2050 estimation, resulted in decreased $>50 \%$ arable area (Wang et al., 2010). Understanding plant responses to drought stress in physiology and morphology will be useful in improving the level of plants tolerance. Rice is the main cereal in Asia and it is providing more than 30\% of consumed calories in Asia. Many of world's rice growing regions lack adequate irrigation and so drought frequently reduces the yield (Kamoshita et al., 2008). Since 1961, the world rice production has been doubled; however, demand for rice is increasing as well (Ke et al., 2009). Plant hormones regulate various aspects of plants to biotic and abiotic stresses (Peleg and Blumwald, 2011). Phytohormones are essential for the ability of plants to adapt to abiotic stresses by mediating a wide range of adaptive responses (Santner and Estelle, 2009; Wang et al., 2009). Although abscisic acid (ABA) has been introduced as hormone regarding to different stresses, the cytokinins (CK), brassinosteroids (BR) and auxin should not be ignored during environmental stresses (Peleg and Blumwald, 2011). IAA (Indole-3-acetic acid) is the carrier of an extended ranges of external and internal signals (Simon and Petrasek, 2011) and it can regulate the plant morphological modifications (Normanly, 2010). The balance of auxin in plants may play a crucial role in response to abiotic stresses (Wang et al., 2010).

In addition, cytokinins had been introduced as a regulator in response to water stress in transgenic tobacco and kinetin proved to be a critical factor in gene expression involving defense mechanisms against drought stress in rice (Xu et al., 2011). Cytokinin is an antagonist regulator regarding to $\mathrm{ABA}$ and the exposure of plants to water limiting conditions results in decreased level of cytokinins

Received: 16 May 2017. Received in revised form: 20 Aug 2017. Accepted: 02 Sep 2017. Published online: 30 Sep 2017. 
(Peleg and Blumwald, 2011). Phenotype consideration is one way to identify drought tolerant plants (Kamoshita $e t$ al., 2008). Just a few researches had been conducted on the impact of stress in vegetative phase of rice life cycle (Kamoshita et al., 2008). If stresses occur in vegetative stage, the plants have more or less time for recovery (Kamoshita $e t$ al., 2008). Pot experiments showed that rice plants in vegetative stage were able to restore a few weeks after facing drought stress (Kamoshita et al., 2004). It has been found that drought stress reduced the height and the number of rice tillers in the vegetative stage (Bocco et al., 2012). The number of tillers is the main differences among rice varieties facing drought stress (Kamoshita et al., 2004).

Leaf greenness plays an important role in leaf photosynthesis activity which is affected by water deficit (Blum, 2000). Degradation of chlorophylls under water deficit can decrease leaf greenness, which will lead to reducing net photosynthesis (Johnson et al., 2002; Guo et al., 2009). Water stress has been associated with high temperature stress that limits crop production (Peleg et al., 2011). Leaf temperature is mostly correlated with a plant stress level and it is a sensitive indicator of a plant water status and associated with leaf stomatal conductance (Jones, 1992). Lower stomatal conductance under drought condition brings a lower transpiration rate, i.e. lower latent heat flux released from the leaves and causes higher leaf temperature (Bocco et al., 2012). The cell membrane integrity under drought stress condition is a sign of control mechanism. If severe plasmolysis occurs during stress, the cell bilayer membranes integrity will collapse, and also lipid peroxidation reduces membrane stability (Jiang and Hung, 2001). Stability of cell membranes plays a critical role in dehydration condition (Xu et al., 2011).

Electrolyte leakage is an important parameter in estimating the stability of the cell membrane. In tolerant varieties, increasing the electrolyte leakage in stress conditions, depend on the extent of damages, is mostly reversible in recovery phase (Xu et al., 2013). Measurement of relative water content (RWC) in leaf is usually applied to indicate the water level in plant and this parameter is used to quantify water deficit in the leaf tissues (Yamasaki and Dillenburg, 1999). It has been reported that drought stress decrease the RWC (Guo et al., 2009; Xu et al., 2013). Chlorophyll fluorescence is also one of the most important ways for assaying environmental stress impacts, and it has been suggested to determinate the tolerance of crops facing drought stress (Moffatt et al., 1990). Environmental stresses such as drought and low temperature induce plants stomatal closure and consequently reduce photosynthetic rate. This event can reduce the electron transfer rate, maximum fluorescence $(\mathrm{Fm})$, variable fluorescence $(\mathrm{Fv})$ and $\mathrm{Fm} / \mathrm{Fv}$ ratio (Maxwell and Johnson, 2000; Baker and Rosenqvist, 2004).

Regarding the importance of drought stress in vegetative stage of different plant genotypes, this research has been carried out to examine some of the physiological and morphological traits of tolerant and sensitive rice genotypes under drought stress, as well as the effect of IAA and Kinetin in improving drought tolerance of the plants.

\section{Materials and Methods}

\section{Study site and treatments}

A factorial pot experiment was carried out based on completely randomized design with three factors and three replications in rain shelter of the Faculty of Agricultural Science, University of Guilan, Iran (49 $36^{\prime}$ E longitude, $37^{\circ} 16^{\prime} \mathrm{N}$ latitude and $7 \mathrm{~m}$ altitude) for two years (2013 and 2014). Factors included four genotypes with differing drought tolerance ('Gharib', 'Khazar', 'Sepidrood' and 'IR83750' ('IR 83750-131-1')), drought stress in two levels (normal irrigation and drought from 1 to 4 code of Vergara coding system) and plant growth regulators (PGRs) in three levels (control (non-application), IAA and Kinetin). 'Sepidrood' and 'IR83750' have been selected as drought tolerant and 'Gharib' and 'Khazar' as sensitive crops (Abarshahr et al., 2011). The seeds were obtained from the Rice Research Institute, Rasht, Guilan, Iran. The seeds where surface sterilized with $\mathrm{NaClO}$ (2\%) for 10 minutes and thoroughly washed with deionized water and then imbibed in deionized water for $12 \mathrm{~h}$ and then incubated for $72 \mathrm{~h}$ at $30{ }^{\circ} \mathrm{C}$ at relative humidity of $70 \%$ for germination. Three seedlings of each genotypes were transplanted in perforated plastic pots $(10 \mathrm{~L})$ filled with $56 \%$ clay, $34 \%$ silt and $10 \%$ sand (Table 1) and fertilized with 50 N, $25 \mathrm{P}$ and $25 \mathrm{~K} \mathrm{mg} \mathrm{mg}^{-1}$. Thereafter, 40 pots (120 plants, including five plants for each treatment) were considered for each replication. The level of water was maintained at $4 \mathrm{~cm}$ above the soil surface. For drought stress treatment, the water siphoned out (10 days after transplanting). After draining, soil water potential was at about -0.8 to $-0.9 \mathrm{MPa}$ (Sharma et al., 2005).

IAA (Indole-3-Acetic Acid, Fluka 279023-1187) and Kinetin (Sigma EC No. 208-382-2) were sprayed on the entire plants except control plants during the vegetative phase (20 days after transplanting) at the evening (after sunset). Each PGRs $\left(5 \times 10^{-5} \mathrm{M}\right)$ was sprayed separately at the rate of $50 \mathrm{ml}$ per plant on the leaves for 2 days.

\section{Traits measurement}

Experimental data were recorded regarding the following traits: tiller number, days to leaf rolling, relative water content, SPAD, electrolyte leakage, leaf temperature, leaf drying score, leaf rolling index, drought recovery and fluorescence parameters. The developed leaves were randomly sampled from each treatment (20 days after drought stress) for chlorophyll measurement. Chlorophyll was measured from the middle section of the fully expanded leaves using a chlorophyll meter (SPAD-502 Minolta, Japan). The average of ten measurements was used for analysis. Number of day to leaf rolling of each plant was recorded as the number of days from the beginning of drought stress to the day when all leaves became rolled at noon. Ordinal traits were measured according to standard evaluation system of IRRI and are explained in Table 2. Five flag leaves were sampled at 10:00 AM (20 days after drought treatment) for RWC measurement. RWC was calculated using the following equation (Ritchie et al., 1990):

RWC $(\%)=\mathrm{Fw}_{\mathrm{w}}-\mathrm{Dw} / \mathrm{Sw}-\mathrm{Dw} \times 100$

Fw: fresh weight of leaf immediately after sampling, Dw: 
380

leaf dried weight, Sw: leaf saturated weight after exposure to distilled water.

Electrolyte leakage was recorded using Molla et al. (2006) method. Leaves were carefully washed and dried for $24 \mathrm{~h}$ at room temperature, and then $1 \mathrm{~cm}^{2}$ of the leaves were putted in $10 \mathrm{ml}$ distilled water. The electrical conductivity of the solution (EL1) was measured after slow stirring for 24 $\mathrm{h}$ at room temperature using EC-meter. The electrical conductivity after autoclave re-read (EL2). The percentage of the electrolyte leakage was calculated using the following equation (Molla et al., 2006):

$$
\mathrm{EL}(\%)=(\mathrm{EL} 1 / \mathrm{EL} 2) \times 100
$$

\section{Fluorescence parameters}

Twenty days after drought treatment, five flag leaves from both irrigated and drought stressed for each genotypes were selected to measure chlorophyll fluorescence parameters and leaf temperature using a portable fluorescence meter (Mini-Pam, Walz, Germany). Fluorescence parameters recorded included F0 which is the initial or minimal fluorescence, a measure of the stability of the light harvesting complex, $\mathrm{Fm}$ and $\mathrm{Fv}(\mathrm{Fv}=\mathrm{Fm}-\mathrm{F} 0)$ are the maximal and variable fluorescence, respectively, $\mathrm{Fv} / \mathrm{Fm}$ represents the maximal quantum yield of PSII, which in turn, is highly correlated with the quantum yield of the net photosynthesis.

\section{Statistical analysis}

Year and year interaction with other factors had no significantly effects on studied traits in ANOVA table, there for the average of two years data was used for increasing the experimental accuracy for the present analysis. Analysis of variance was performed using SAS (version 9.2) and Minitab (version 14). Tukey test was used to test the

Table 1. Soil properties of the present study

\begin{tabular}{cc}
\hline Characteristics & Size \\
\hline $\mathrm{pH}$ & 6.1 \\
$\mathrm{EC}$ & 138.4 us.m \\
\hline Soil texture & Clay \\
\hline Nitrogen & $0.216 \%$ \\
\hline Phosphorus & 15.2 part per million \\
\hline Potassium & 21 part per million \\
\hline Dry bulk density & 1.1 \\
\hline Particle density & 2.83 \\
\hline Organic material & 5.66 \\
\hline Porosity & 65.75 \\
\hline Carbon & $3.28 \%$ \\
\hline
\end{tabular}

Table 2. Description of the ordinal traits used in current study

\begin{tabular}{cccc}
\hline \multirow{2}{*}{ Score } & & Ordinal traits & Drought recovery \\
\cline { 2 - 4 } & Leaf drying score & Leaf rolling index & - \\
\hline 0 & no symptoms & leaves healthy & 90 to $100 \%$ \\
1 & Just the leaves tip burned & leaves starting to fold (shallow V-shape) & 70 to $89 \%$ \\
5 & more than a quarter of the most leaves & leaves folding (deep V-shape) & 40 to $69 \%$ \\
7 & one-fifth to one-half of all leaves burned & leaves fully cupped (U-shape) & 20 to $39 \%$ \\
9 & more than two-thirds of all the leaves are burned & leaf margins touching (O-shape) & 0 to $19 \%$ \\
\hline
\end{tabular}

differences between the means. Percentage data were data and back-transformed data are presented in the tables.

\section{Results}

The results showed that the highest numbers of tillers (18.27) was recorded in 'IR83750' and IAA application in normal irrigation. In stress conditions, the lowest number of tillers with a mean of 5.88 belonged to 'Gharib' and nonapplication of growth regulators (Table 3). In general, drought stress in vegetative stage decreased the number of tillers in all genotypes. Results indicated that under drought stress at vegetative stage, 'Gharib' and 'Khazar' showed days to leaf rolling after 9.3 and 9.7 days of drought stress, respectively, while 'Sepidrood' and 'IR83750' showed days to leaf rolling after 17.02 and 16.61 days, respectively (Fig. 1). The results showed that 'Gharib' and 'Khazar' reacted to drought stress earlier than 'Sepidrood' and 'IR83750'. The growth regulators (IAA and Kin) application increased the number of days to leaf rolling (Fig. 1).

According to the current results, the lowest relative water content was observed in 'Gharib' under drought stress and without regulator application with a mean of $29.07 \%$. The highest relative water content $(95.11 \%)$ was attained from 'Sepidrood' under normal irrigation along with IAA application. In general, in drought conditions, 'Sepidrood' and 'IR83750' had more RWC than 'Gharib' and 'Khazar'. Meanwhile, the results showed that the highest amount of leaf greenness belonged to 'IR83750' in normal irrigation along with an IAA application with a mean of 49.46, while the lowest amount belonged to 'Gharib' in drought stress condition without regulator application with a mean of 26.96 (Table 3). In drought stress condition, the highest electrolyte leakage was observed in 'Gharib' without regulators with a mean of $36.59 \%$ and the lowest electrolyte leakage (15.75\%) in 'IR83750' along with IAA application and normal irrigation (Table 3 ).

In drought conditions, the leaves of 'Gharib' genotype had the highest temperature $\left(36.36{ }^{\circ} \mathrm{C}\right)$ without the application of regulators, while in normal irrigation, the lowest temperature $\left(29.29^{\circ} \mathrm{C}\right)$ belonged to 'Khazar', 'Gharib' and 'Sepidrood' along with the kinetin application (Table 3). Non-parametric analysis showed that there was a significant difference among treatments (Table 4). In drought conditions, the highest drying score of leaf (rank 7) belonged to 'Gharib' without regulator application (Table 5). 'Gharib' and 'Khazar' had the highest leaf rolling index (rank 9) as well as the highest DRR (drought recovery) without growth regulator application (Table 5). The results showed that 'IR83750' and 'Sepidood' compensated lots of transformed into arcsin prior to the statistical analysis of 

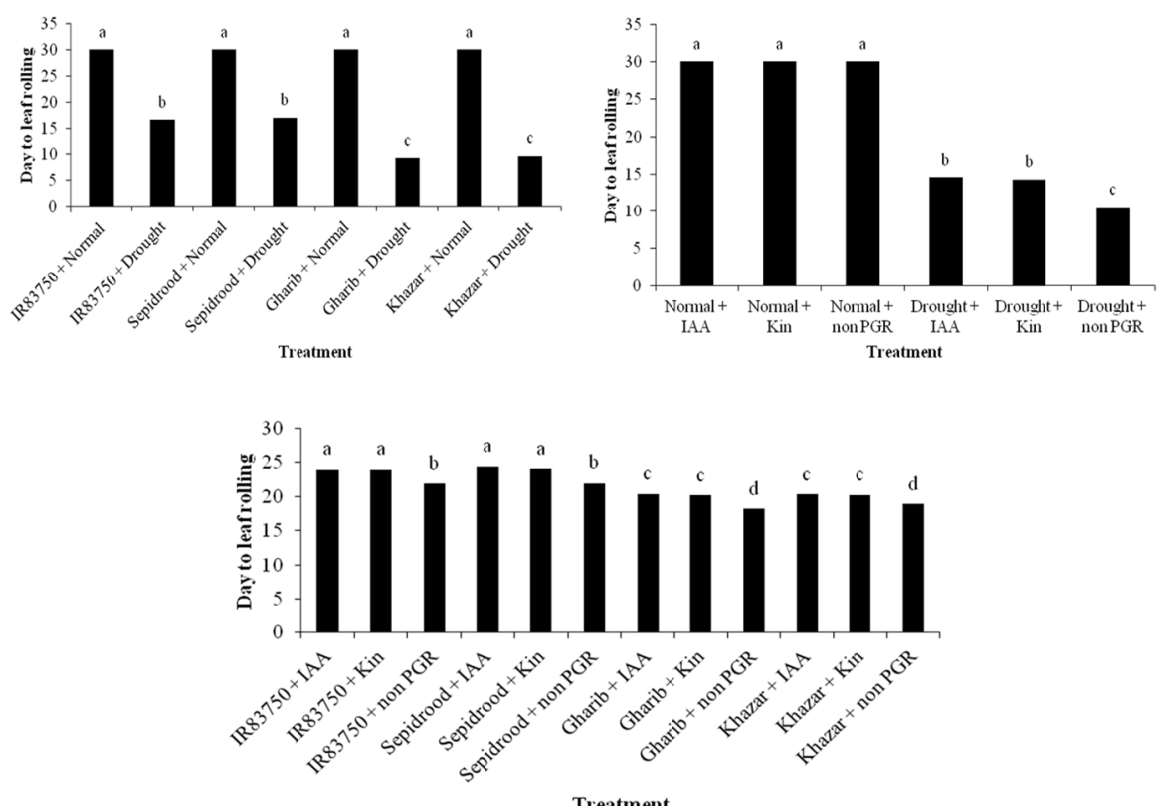

Fig. 1. Effects of the treatments on day to leaf rolling (means in each bar followed by similar letter(s) are not significantly different, using Tukey Test. IAA: Indole-3-Acetic Acid, Kin: Kinetin, PGR: plant growth regulator)
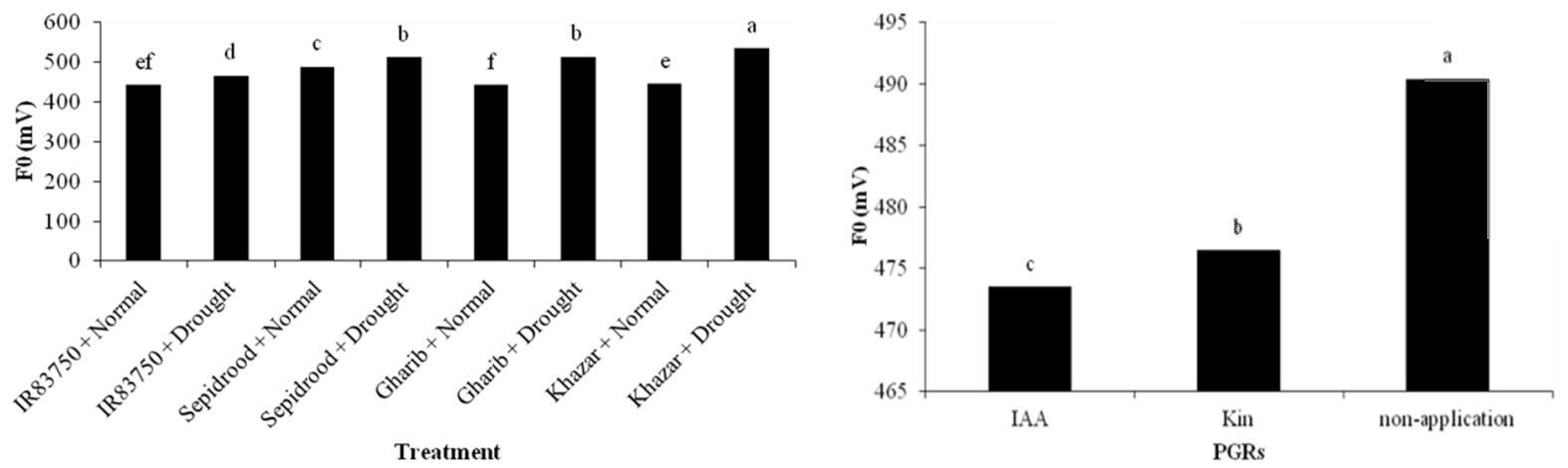

Fig. 2. Effects of the treatments on minimum fluorescence (F0) (Means in each bar followed by similar letter(s) are not significantly different, using Tukey Test. IAA: Indole-3-Acetic Acid, Kin: Kinetin, PGR: plant growth regulator)

Table 3. Mean comparisons of the effect of genotype $\times$ stress $\times$ PGRs interaction on the studied traits in the rice genotypes

\begin{tabular}{|c|c|c|c|c|c|c|c|c|c|c|}
\hline Genotypes & Stress & PGRs & Tiller No. & RWC (\%) & SPAD & $\mathrm{LT}\left({ }^{\circ} \mathrm{C}\right)$ & EL (\%) & $\mathrm{Fm}(\mathrm{mV})$ & $\mathrm{Fv}(\mathrm{mV})$ & $\mathrm{Fv} / \mathrm{Fm}$ \\
\hline \multirow{6}{*}{ 'IR83750’ } & \multirow{3}{*}{ Normal } & Non-PGR & $17.05^{a-d}$ & $88.28^{e}$ & $46.46^{a-d}$ & $30.34^{\mathrm{h}}$ & $18.56^{g}$ & $1978.5^{\circ}$ & $1525.5^{n}$ & $0.771^{\mathrm{n}}$ \\
\hline & & IAA & $18.27^{\mathrm{a}}$ & $92.2^{\mathrm{b}-\mathrm{d}}$ & $49.46^{\mathrm{a}}$ & $29.32^{i}$ & $15.75^{\mathrm{h}}$ & $2092^{1}$ & $1655.1^{1}$ & $0.791^{i}$ \\
\hline & & Kin & $17.88^{\mathrm{ab}}$ & $91.15^{\text {b-e }}$ & $48.26^{\mathrm{ab}}$ & $30.29^{\mathrm{h}}$ & $16.55^{\mathrm{gh}}$ & $2077.8^{\mathrm{m}}$ & $1638^{\mathrm{m}}$ & $0.788^{k}$ \\
\hline & \multirow{3}{*}{ Drought } & Non-PGR & $11.8^{\mathrm{h}-\mathrm{k}}$ & $38.16^{j}$ & $36.76^{\mathrm{ij}}$ & $32.34^{e}$ & $30.69^{\mathrm{bc}}$ & $1461.8^{r}$ & $985.3^{r}$ & $0.674^{r}$ \\
\hline & & IAA & $13.5^{\mathrm{fi}_{\mathrm{i}}}$ & $48.06^{\mathrm{gh}}$ & $39.16^{f_{i}}$ & $31.33^{\mathrm{g}}$ & $26.59^{\text {ef }}$ & $1842.3^{\mathrm{P}}$ & $1382.3^{p}$ & $0.750^{\circ}$ \\
\hline & & Kin & $13.27^{\mathrm{f}-j}$ & $45.96^{\mathrm{h}}$ & $38.71^{f-i}$ & $31.29 \mathrm{~g}$ & $27.09^{\mathrm{ef}}$ & $1734.6^{9}$ & $1272^{q}$ & $0.733^{9}$ \\
\hline \multirow{6}{*}{ 'Sepidrood' } & \multirow{3}{*}{ Normal } & Non-PGR & $16.27^{a-e}$ & $91.15^{\mathrm{b}-\mathrm{e}}$ & $41.64^{\mathrm{ef}}$ & $30.3^{\mathrm{h}}$ & $17.81^{\mathrm{gh}}$ & $2421.5^{\mathrm{h}}$ & $1923.5^{\mathrm{h}}$ & $0.749^{i}$ \\
\hline & & IAA & $17.86^{\mathrm{ab}}$ & $95.11^{a}$ & $45.9^{\mathrm{b}-\mathrm{d}}$ & $29.32^{i}$ & $16.09^{\mathrm{gh}}$ & $2530.3^{e}$ & $2049.2^{f}$ & $0.809^{f}$ \\
\hline & & Kin & $17.39^{a-c}$ & $92.78^{a-c}$ & $44.21^{\mathrm{de}}$ & $29.29^{i}$ & $16.56^{\mathrm{gh}}$ & $2493.3^{\mathrm{g}}$ & $2008.7^{\mathrm{g}}$ & $0.805^{\mathrm{g}}$ \\
\hline & \multirow{3}{*}{ Drought } & Non-PGR & $11.27^{\mathrm{ik}}$ & $40.6^{\mathrm{i}}$ & $37.46^{\mathrm{h}-\mathrm{j}}$ & $31.84^{f}$ & $31.54^{\mathrm{b}}$ & $2011^{\mathrm{n}}$ & $1488.91^{\circ}$ & $0.740^{\mathrm{P}}$ \\
\hline & & IAA & $15.08^{\mathrm{c-f}}$ & $51.26^{f}$ & $40.01^{\text {fh }}$ & $30.33^{\mathrm{h}}$ & $25.79^{f}$ & $2353.8^{\mathrm{i}}$ & $1848.4^{\mathrm{i}}$ & $0.785^{1}$ \\
\hline & & Kin & $13.66^{\mathrm{fhh}}$ & $50.19^{\mathrm{gg}}$ & $39.66^{6.1}$ & $31.29^{\mathrm{g}}$ & $27.59^{\mathrm{d} \cdot \mathrm{f}}$ & $2322^{j}$ & $1813.9^{j}$ & $0.781^{\mathrm{m}}$ \\
\hline \multirow{6}{*}{ 'Gharib' } & \multirow{3}{*}{ Normal } & Non-PGR & $12.05^{\mathrm{g} \cdot \mathrm{k}}$ & $89.2^{\mathrm{de}}$ & $40.81^{f_{g}}$ & $30.3^{\mathrm{h}}$ & $18.33^{g}$ & $2508^{f}$ & $2055.6^{e}$ & $0.819^{\mathrm{c}}$ \\
\hline & & IAA & $14.87^{\mathrm{d} \cdot \mathrm{f}}$ & $93.39^{\mathrm{ab}}$ & $47.11^{1-d}$ & $29.3^{i}$ & $17.61^{\mathrm{gh}}$ & $2842.5^{\mathrm{a}}$ & $2408^{a}$ & $0.847^{\mathrm{a}}$ \\
\hline & & Kin & $14.2^{e-g}$ & $91.8^{\mathrm{b}-\mathrm{d}}$ & $44.61^{\mathrm{cee}}$ & $29.29^{\mathrm{i}}$ & $18.04^{\mathrm{gh}}$ & $2804^{\mathrm{b}}$ & $2366.3^{b}$ & $0.843^{b}$ \\
\hline & \multirow{3}{*}{ Drought } & Non-PGR & $5.88^{\mathrm{l}}$ & $29.7^{i}$ & $26.96^{1}$ & $36.36^{a}$ & $36.59^{a}$ & $1224.3^{\mathrm{w}}$ & $701.2^{\mathrm{v}}$ & $0.572^{\mathrm{w}}$ \\
\hline & & IAA & $10.5^{\mathrm{k}}$ & $38.91^{i}$ & $34.41^{\mathrm{jk}}$ & $33.3^{d}$ & $28.69^{c \cdot e}$ & $1443.5^{\mathrm{s}}$ & $937.41^{\mathrm{s}}$ & $0.649^{\mathrm{s}}$ \\
\hline & & Kin & $10.11^{\mathrm{k}}$ & $38.16^{\mathrm{i}}$ & $33.66^{k}$ & $34.29^{c}$ & $29.89^{\mathrm{b}-\mathrm{d}}$ & $1405.6^{u}$ & $896.9^{x}$ & $0.638^{\mathrm{t}}$ \\
\hline \multirow{6}{*}{ 'Khazar' } & \multirow{3}{*}{ Normal } & Non-PGR & $15.61^{b-f}$ & $90.03^{c-e}$ & $45.16^{\text {b-d }}$ & $30.34^{\mathrm{h}}$ & $17.68^{\mathrm{gh}}$ & $2255.8^{\mathrm{k}}$ & $1800.3^{\mathrm{k}}$ & $0.798^{\mathrm{h}}$ \\
\hline & & IAA & $16.83^{\mathrm{a}} \mathrm{-}^{\mathrm{d}}$ & $93.06^{a-c}$ & $47.41^{a-c}$ & $29.3^{\mathrm{i}}$ & $16.58^{\text {gh }}$ & $2627^{c}$ & $2189^{c}$ & $0.833^{c}$ \\
\hline & & Kin & $16.30^{2-e}$ & $92.28^{a-d}$ & $46.9^{a-d}$ & $29.29^{i}$ & $16.88^{\mathrm{gh}}$ & $2550.8^{\mathrm{d}}$ & $2109.8^{\mathrm{d}}$ & $0.827^{\mathrm{d}}$ \\
\hline & \multirow{3}{*}{ Drought } & Non-PGR & $6.5^{1}$ & $32.3^{j}$ & $34.41^{j k}$ & $35.35^{b}$ & $31.44^{\mathrm{b}}$ & $1223^{\mathrm{w}}$ & $679.5^{\mathrm{w}}$ & $0.555^{x}$ \\
\hline & & IAA & $11.33^{\mathrm{h}-\mathrm{k}}$ & $40.96^{i}$ & $38.61^{f-i}$ & $33.3^{d}$ & $27.19^{\mathrm{ef}}$ & $1423^{t}$ & $896.4^{t}$ & $0.629^{u}$ \\
\hline & & Kin & $11.11^{\mathrm{jk}}$ & $40.06^{\mathrm{i}}$ & $37.86^{g-i}$ & $34.29^{c}$ & $27.69^{\mathrm{d} \cdot \mathrm{f}}$ & $1377.3^{v}$ & $847.7^{u}$ & $0.615^{v}$ \\
\hline
\end{tabular}

Means in each column followed by similar letter(s) are not significantly different, using Tukey Test. RWC: relative water content, SPAD: leaf greenness, LT: leaf temperature, EL: Electrolyte leakage, Fm: maximum fluorescence, Fv: variable fluorescence, Fv/Fm: quantum yield 
382

Table 4. Chi-square amount in Freedman's Non-parametric test for ordinal measurement traits

\begin{tabular}{ccccc} 
& Degrees of freedom & Leaf drying score & Leaf rolling index & Drought recovery \\
\hline Chi-square & 47 & $121.21^{* *}$ & $121.47^{* *}$ & $99.63^{* *}$ \\
${ }^{* *}$, significant at 1\% probability level & & &
\end{tabular}

Table 5. Means of ordinal measurement traits in all examined genotypes under drought stress

\begin{tabular}{|c|c|c|c|c|c|c|}
\hline Year & Genotypes & Stress & PGRs & LDS & LRI & DRR \\
\hline \multirow{24}{*}{2013} & \multirow{6}{*}{ 'IR83750’ } & \multirow{3}{*}{ Normal } & Non-PGR & 0 & 0 & 1 \\
\hline & & & IAA & 0 & 0 & 1 \\
\hline & & & Kin & 0 & 0 & 1 \\
\hline & & \multirow{3}{*}{ Drought } & Non-PGR & 3 & 5 & 3 \\
\hline & & & IAA & 1 & 1.04 & 1 \\
\hline & & & Kin & 1 & 3 & 1.12 \\
\hline & \multirow{6}{*}{ 'Sepidrood' } & \multirow{3}{*}{ Normal } & Non-PGR & 0 & 0 & 1 \\
\hline & & & IAA & 0 & 0 & 1 \\
\hline & & & Kin & 0 & 0 & 1 \\
\hline & & \multirow{3}{*}{ Drought } & Non-PGR & 3 & 5.08 & 3 \\
\hline & & & IAA & 1 & 3 & 1 \\
\hline & & & Kin & 1 & 3 & 1.91 \\
\hline & \multirow{6}{*}{ 'Gharib' } & \multirow{3}{*}{ Normal } & Non-PGR & 0 & 0 & 1 \\
\hline & & & IAA & 0 & 0 & 1 \\
\hline & & & Kin & 0 & 0 & 1 \\
\hline & & \multirow{3}{*}{ Drought } & Non-PGR & 7 & 9 & 7 \\
\hline & & & IAA & 4.8 & 5.08 & 5 \\
\hline & & & Kin & 5 & 5 & 4.95 \\
\hline & \multirow{6}{*}{ 'Khazar' } & \multirow{3}{*}{ Normal } & Non-PGR & 0 & 0 & 1 \\
\hline & & & IAA & 0 & 0 & 1 \\
\hline & & & Kin & 0 & 0 & 1 \\
\hline & & \multirow{3}{*}{ Drought } & Non-PGR & 5.08 & 9 & 7 \\
\hline & & & IAA & 3 & 5.08 & 4.91 \\
\hline & & & Kin & 4.89 & 5.08 & 5 \\
\hline \multirow{24}{*}{2014} & \multirow{6}{*}{ 'IR83750’ } & \multirow{3}{*}{ Normal } & Non-PGR & 0 & 0 & 1 \\
\hline & & & IAA & 0 & 0 & 1 \\
\hline & & & Kin & 0 & 0 & 1 \\
\hline & & \multirow{3}{*}{ Drought } & Non-PGR & 3 & 5 & 3 \\
\hline & & & IAA & 1 & 2.7 & 1 \\
\hline & & & Kin & 1 & 3 & 1 \\
\hline & \multirow{6}{*}{ 'Sepidrood' } & \multirow{3}{*}{ Normal } & Non-PGR & 0 & 0 & 1 \\
\hline & & & IAA & 0 & 0 & 1 \\
\hline & & & Kin & 0 & 0 & 1 \\
\hline & & \multirow{3}{*}{ Drought } & Non-PGR & 3 & 6.7 & 3 \\
\hline & & & IAA & 1 & 1.08 & 1 \\
\hline & & & Kin & 2.02 & 1.04 & 1.16 \\
\hline & \multirow{6}{*}{ 'Gharib' } & & Non-PGR & 0 & 0 & 1 \\
\hline & & Normal & IAA & 0 & 0 & 1 \\
\hline & & & Kin & 0 & 0 & 1 \\
\hline & & & Non-PGR & 7 & 9 & 7 \\
\hline & & Drought & IAA & 3.04 & 5.08 & 5 \\
\hline & & & Kin & 5 & 5 & 5 \\
\hline & & & Non-PGR & 0 & 0 & 1 \\
\hline & & Normal & IAA & 0 & 0 & 1 \\
\hline & 'Khazar' & & Kin & 0 & 0 & 1 \\
\hline & & & Non-PGR & 5 & 9 & 7 \\
\hline & & Drought & IAA & 3 & 7 & 4.91 \\
\hline & & & Kin & 3.08 & 7 & 5 \\
\hline
\end{tabular}


harmful effects due to drought stress, and 10 days before rewatering returned almost at normal growing conditions. These genotypes, 10 days after the re-watering acquired 70 to $89 \%$ of normal growth condition, while, 'Gharib' and 'Khazar' achieved only 20 to $39 \%$ of normal growth condition. The above results were the same for both the experimental years.

Additionally, the results indicated that F0 was higher in non-application of regulators than the other values (Fig. 2). In normal irrigation, 'Gharib' had the highest Fm (2,842.5 $\mathrm{mV}$ ) along with IAA application. In drought condition, the lowest Fm $(1,223 \mathrm{mV})$ belonged to 'Khazar' without regulator application (Table 3 ). In normal irrigation, the highest Fv $(2,408 \mathrm{mV})$ was acquired from 'Gharib' and IAA application (Table 3). The results showed that in normal irrigation, photochemical efficiency of photosystem II with a mean of 0.847 belonged to 'Gharib' along with the application of IAA (Table 3 ).

\section{Discussion}

Drought stress due to the reduction of water uptake leads to decreased plant's ability to anatomical and physiological development. According to the current research, drought stress decreased the number of tillers about $50 \%$ in 'Gharib' and 'Khazar' while in 'IR83750' the reduction was about 3\%. Decreasing the number of tillers in 'Sepidrood' and 'IR83750' was less than for 'Gharib' and 'Khazar'. These genotypes maintained their water content probably via faster stomatal closure or more water absorption than the other two examined genotypes. These results are in agreement with the findings showing that drought stress decrease the number of tillers (Kamoshita $e t$ al., 2004; Bocco et al., 2012).

Although stress reduced resources available for rice plants, but according to the current results, the application of IAA and Kin through improving stress tolerance of the plants increased the number of tillers in all genotypes. Liu $e t$ al. (2001) also reported that the regulator of Kin had increased the number of tillers in rice. The first response to drought in rice is leaf rolling (Sie et al., 2008), which is a consequence of turgor loss of the plant (Zinolabedin et al., 2008). Rice roll leaves to maintain a favorable RWC under drought. The genotypes with high leaf rolling ability or with high leaf water maintenance potential during drought will be able to yield better than sensitive genotypes (Fukai and Cooper, 2002). The high RWC and low EL in 'Sepidrood' and 'IR83750' (tolerant to drought) confirmed this statement. The results indicated that under drought stress, both tolerant and sensitive genotypes showed leaf rolling. Thus, leaf rolling, RWC and EL are good indicators of drought stress level.

It has been found that the application of IAA and Kin decreased the leaf rolling in rice (Yue et al., 2006). Their exogenous application provides an approach to control the stress. Also, reduction in the endogenous kinetin under stress conditions points towards the possibility that kinetin levels could be a limiting factor under stress conditions. These regulators improved the physiological functions of the plants. The regulators through increasing relative water content decreased the leaf rolling. Fast leaf rolling created by the lack of adequate cellular water content, is a reaction of sensitive plants to stress. With normal irrigation, leaf rolling index was zero for all genotypes, but in drought conditions in the non application of the regulators, leaf rolling index was at least 5 (Table 5). Thus, it can be concluded that leaf rolling index of 5 can be considered for the occurrence of drought stress in rice. Probably, inability to control the stomatal conductance could lead to water loss and reduction of leaf relative water content in rice. The genotypes that are more tolerant against stress can better manage stress by controlling their stomatal conductance.

Reducing the leaf relative water content during stress can decrease photosynthesis and membrane stability in rice (Deivanai et al., 2010). In normal irrigation conditions, 'Gharib' had leaf RWC with a mean of $89.2 \%$ without exogenous application of the regulators, while in drought stress it reached to $29.7 \%$ (about $77 \%$ of reduction in RWC) without the application of the regulators. But, this reduction in 'Sepidrood' was about 55\% (Table 3). In other word, 'Sepidrood' and 'IR83750' could manage better drought stress than 'Gharib' and 'Khazar', losing less water. This effect has been previously reported (Zulkarnain et al., 2009; Abarshahr et al., 2011). The application of IAA and Kin in all examined genotypes led to increasing leaf RWC. Probably, the positive impact of the two growth regulators in the plant's roots led to increased water uptake from the soil (Zhu et al., 2011). Increasing RWC through the application of IAA and Kin created normal conditions for the plants, improving growth in these conditions. In general, the application of IAA and Kin play an important role in plant tolerance facing drought stress. Increasing RWC by application of IAA in 'IR83750', 'Sepidrood', 'Gharib' and 'Khazar' were 30, 26.5, 31 and 29\%, respectively. Although, the growth regulators could not create full recovery for the plants, they could recover partial incoming damages. Other researchers have also reported that the application of IAA and Kin improved plant growth condition in drought stress (Yue et al., 2006; Ghorbani et al., 2011). In drought stress condition, 'Sepidrood' and 'IR83750' had more greener than the sensitive genotypes ('Gharib' and 'Khazar'). Bocco et al. (2012) reported the genotypes that have a constant photosynthetic activity or maintained their leaf greenness under drought stress can be assumed as more or less tolerant under drought stress. The present results confirm this statement. The application of IAA and Kin had positive effect on the leaf greenness improving the plant growth. This result is in agreement with the findings of Normanly (2010).

Apparently, drought stress, through the destruction of the cell membrane phospholipids, increased electrolyte leakage in all the examined genotypes. The tolerant genotypes ('IR83750' and 'Sepidrood') had lower electrolyte leakage than the sensitive genotypes ('Khazar' and 'Gharib'). 'Sepidrood' and 'IR83750' with lower electrolyte leakage showed greater tolerance against membrane destruction than the other two examined genotypes. The present results were consistent with the results of $\mathrm{Xu}$ et al. (2013). The evaluation of the leaf RWC and EL can indicate the level of drought effect on the plants, in addition to the morphological characteristics such as leaf rolling. The application of growth regulators through increasing RWC and controlling stomatal conductance decreased leaf 
384 temperature, maintaining membrane integrity and decreasing the electrolyte leakage in all studied genotypes. It has been reported that the water deficit is always associated with high temperature stress reducing the plant production (Peleg et al., 2011).

There is a significant correlation between leaf temperature and the yield of rice (Guimaraes et al., 2010; Bocco et al., 2012). The current results indicated that 'Gharib' and 'Khazar' had a higher leaf drying score than 'Sepidrood' and 'IR83750'. These genotypes had higher EL and lower RWC due to losing the cell membrane integrity and consequently failing to maintain their water balance, ruptured. It has previously been reported that drought stress increased the leaf drying score in 180 studied inbred lines (Yue et al., 2006). The exogenous application of IAA and Kin on 'Gharib' decreased the leaf drying score from 7 to 3 and 5, respectively (Table 5). The regulators affected on the shoot and root, leading to higher water uptake or retention of water in the shoot, thus the balance of water fluctuated less in plant and leaf drying score declined. The leaf drying score is the morphological symptom of increasing and decreasing the leaf RWC and EL, respectively. Reducing the RWC can be a major factor in leaf rolling (Zinolabedin $e t$ al., 2008), because reducing the amount of RWC in leaves decrease turgor pressure and leaf rolling. The plants recovery after drought stress usually occurs in 10 days after normal irrigation (Bogeat-Triboulot et al., 2007).

The application of IAA and Kin in 'Gharib' led to 40 and $69 \%$ recovery, respectively. In drought conditions due to the closure of stomata and water deficit, plants would have a lower rate of photosynthesis. The current results showed that the application of IAA and Kin decreased F0. Opening of reaction centers means the reduction of photosynthetic rate, but the application of IAA and Kin improved the plant growth through controlling the stomata conductance and increasing RWC.

In drought condition, 'Khazar' and 'Gharib' had more F0 ( 533.1 and $441.5 \mathrm{mV}$, respectively) than the other two examined genotypes. Sensitive genotypes had less control on stomata opening than tolerant genotypes. Increasing F0 revealed that, plants expose of stress and the reaction centers are open. There are no electrons for reduction of quinone $A$ (QA), thus the plant felling starvation. Fm or maximum chlorophyll fluorescence represented a maximum value of reduced QA. According to the results found in this study, drought stress decreased Fm and Fv (the variable fluorescence of chlorophyll) in all examined genotypes. Drought stress, due to stomata closure and lack of electron required for electron transport chain, increase chlorophyll fluorescence. Decreasing light use efficiency leads to decrease PSII photochemical. Pandey and Shukla (2015) reported that a decrease in maximum quantum yield may occur due to stress-induced impairment in pigment biosynthetic pathways or in pigment degradation. Fv, Fm and $\mathrm{Fv} / \mathrm{Fm}$ in rice treated with IAA and Kin increased and F0 decreased. These regulators provide the suitable condition for $\mathrm{CO}_{2}$ entry and water uptake. In drought condition, the electron transport chain is ruptured and the production of NADPH and ATP is blocked. According to the current results, the exogenous application of growth regulators increased $\mathrm{Fm}$ and $\mathrm{Fv}$. These regulators increased $\mathrm{RWC}$ and the stomatal conductance increasing $\mathrm{CO}_{2}$ uptake and photosynthesis (Maisura et al., 2014). In general, the current study showed that 'IR83750' and 'Sepidrood' were more tolerant than 'Gharib' and 'Khazar', and the application of IAA and Kin improved the drought stress tolerance in all studied genotypes.

\section{Conclusions}

The hereby study showed that 'IR83750'and 'Sepidrood' were more tolerant to drought stress than 'Gharib' and 'Khazar' genotype, and the application of IAA and Kin improved the drought stress tolerance in all studied genotypes.

\section{References}

Abarshahr M, Rabiei B, Samizadeh Lahiji H (2011). Assessing genetic diversity of rice varieties under drought stress conditions. Notulae Scientia Biologicae 3:114-123.

Baker NR, Rosenqvist E (2004). Applications of chlorophyll fluorescence can improve crop production strategies: an examination of future possibilities. Journal of Experimental Botany 55:1607-1621.

Blum A (2000). Drought tolerance is it a complex trait? In: Saxena NP, O'Toole JC (Eds). Field Screening for Drought Tolerance in Crop Plants with Emphasis on Rice: Proceedings of an International Workshop on Field Screening for Drought Tolerance in Rice 11-14 December 2000, Patancheru: International Crops Research Institute for the Semi-Arid Tropics (ICRISAT), Patancheru, India pp 17-22.

Bocco R, Lorieux M, Seck PA, Futakuchi K, Manneh B, Baimey H, Ndjiondjop MN (2012). Agro-morphological characterization of a population of introgression lines derived from crosses between IR 64 (Oryza sativa indica) and TOG 5681 (Oryza glaberrima) for drought tolerance. Plant Science 183:65-76.

Bogeat-Triboulot MB, Brosche M Renaut J, Jouve L, Le Thiec D, Fayyaz P (2007). Gradual soil water depletion results in reversible changes of gene expression, protein profiles, ecophysiology, and growth performance in Populus exphratica, a poplar growing in arid regions. Plant Physiology 143:876-892.

Deivanai S, Sheela Devi S, Sharmmil RP (2010). Physiochemical traits as potential indicators for determining drought tolerance during active tillering stage in rice (Oryza sativa L.). Pertanika Journal of Tropical Agricultural Science 33(1):61-70.

Farooq M, Wahid A, Basra SMA, Din ID (2009). Improving water relations and gas exchange with brassinosteroids in rice under drought stress. Journal of Agronomy Crop Science 195:262-269.

Fukai S, Cooper M (2002). Field screening of adaptability in drought-prone rain- 845 fed lowland rice: ACIAR experience in Thailand and Laos. In: Saxena NP, O’Toole JC (Eds). Field Screening for Drought Tolerance in Crop Plants with Emphasis on Rice: Proceedings of an International Workshop on Field Screening for Drought Tolerance in Rice, 11-14 December 2000, Patancheru: International Crops Research Institute for the Semi-Arid Tropics(ICRISAT), Patancheru, India, pp 61-62.

Ghorbani Javid M, Sorooshzadeh A, Moradi F, Modarres Sanavy SAM, Allahdadi I (2011). The role of phytohormones in alleviating salt stress in crop plants. Australian Journal of cropScience 5(6):726-734. 
Guimaraes CM, Stone LF, Lorieux M, Oliveira JPD, Alencar GCDO, Dias RAA (2010). Infrared thermometry for drought phenotyping of inter and intra specific rice lines. Revista Brasileira de Engenharia Agrícola e Ambiental 14(2):148-154.

Guo P, Baum M, Grando S, Ceccarelli S, Bai G, Li R, Von Korff M, Varshney RK, Graner A, Valkoun J (2009). Differentially expressed genes between drought-tolerant and drought-sensitive barley genotypes in response to drought stress during the reproductive stage. Journal of Experimental Botany 60:3531-3544.

Jiang Y, Hung B (2001). Drought and heat stress injury to two cool-season turfgrass in relation to antioxidant metabolism lipid peroxidation. Crop Science 41:436-442.

Johnson R, Frey NM, Dale N (2002). Effect of water stress on photosynthesis and transpiration of flag leaves and spikes of barley and wheat. CropScience 5:728-731.

Jones HG (1992). Plants and Microclimate 2. Cambridge Univ. Press, Cambridge.

Kamoshita A, Chandra Babu R, Manikanda Boopathi N, Fukai S (2008). Phenotypic and genotypic analysis of drought-resistance traits for development of rice cultivars adapted to rainfed environments. Field Crops Research 109:1-23.

Kamoshita A, Rodriguez R, Yamauchi A, Wade LJ (2004). Genotypic variation in response of rainfed lowland rice to prolonged drought and re-watering. Plant Production Science 7:406-420.

Ke Y, Han G, He H, Li J (2009). Differential regulation of proteins and phosphoproteins in rice under drought stress. Biochemical and Biophysical Research Communication 379(1):133-138.

Liu Z, Goto Y, Nishiyama I, Kokubun M (2001). Effects of foliar and rootapplied benzylaminopurine on tillering of rice plants grown in hydroponics. Plant Production Science 4:220-226.

Maxwell k, Johnson GN (2000). Chlorophyll fluorescence-a practical guide. Journal of Experimental Botany 345:659-668.

Moffat JM, Sears G, Cox TS, Paulsen GM (1990). Wheat high temperature tolerance during reproductive growth. I. Evaluation by chlorophyll fluorescence. CropScience 30:881-885.

Molla S, Villar-Salvador P, Garcia-Fayos P, Penuelas Rubira JL (2006). Physiological and transplanting performance of Quercus ilex L. (holm oak) seedlings grown in nurseries with different winter conditions. Forest Ecology and Management 237:218-226.

Normanly J2(010). Approaching cellular and molecular resolution of auxin biosynthesis and metabolism. Cold Spring Harbor Perspectives in Biology 2:1-18.

Peleg Z, Blumwald E (2011). Hormone balance and abiotic stress tolerance in crop plants. Current Opinion in Plant Biology 14(3):290-295.

Peleg Z, Reguera M, Tumimbang E, Walia H, Blumwald E (2011). Cytokinin-mediated source/sink modifications improve drought tolerance and increase grain yield in rice under water-stress. Plant Biotechnology Journal 1-12.

Ritchie SW, Nguyen HT, Haloday AS (1990). Leaf water content and gas exchange parameters of two wheat genotypes differing in drought resistance. CropScience 30:105-111.
Santner A, Estelle M (2009). Recent advances and emerging trends in plant hormone signalling. Nature 459:1071-1078.

Sharma P, Dubey RS (2005). Drought induces oxidative stress and enhances the activities of antioxidant enzymes in growing rice seedlings. Plant Growth Regulator 46:209-221.

Sie M, Futakuch, K, Gridley H, Mande S, Manneh B, Ndjiondjop MN, Efisue A, Ogunbayo SA, Moussa M, Tsunematsu H, Samejima H (2008). Drought research at WARDA: Current Situation and Prospects. In: Serraj R, Bennett J, Hardy B (Eds). Drought Frontiers in Rice: Crop Improvement for Increased Rainfed Production, International Rice Research Institute(IRR), Los Banos pp 61-73.

Simon S, Petrasek J (2011). Why plants need more than one type of auxin. Plant Science 180:454 460.

Wang H, Zhang L, Ma J, Li X, Li Y, Zhang R, Wang R (2010). Effects of Water Stress on Reactive Oxygen Species Generation and Protection System in Rice during Grain-Filling Stage. Agricultural Science in China 9(5):633-641.

WangL, WangZ, Xu Y,JooSH,Kim SK, XueZ, XuZ, WangZ, ChongK (2009). OsGSR1 is involved in crosstalk between gibberellins and brassinosteroids in rice. The Plant Journal 57:498-510.

Wu N, Guan Y, Shi Y (2011). Effect of water stress on physiological traits and yield in rice backcross lines after anthesis. Energy Procedia 5:255260.

Xu L, Yu J, Han L, Huang B (2013). Photosynthetic enzyme activities and gene expression associated with drought tolerance and post-drought recovery in Kentucky bluegrass. Environmental and Experimental Botany 89:28-35.

Xu L, Han L, Huang B (2011). Antioxidant enzyme activities and gene expression patterns in leaves of Kentucky bluegrass in response to drought and post drought recovery. Journal of the American Society for Horticultural Science 136:247-255.

Yamasaki S, Dillenburg LR (1999). Measurment of leaf relative water content in Araucaria Angustifolia. Revista Brasileira de Fisiologia Vegetal 11(2):69-75.

Yue B, Xue W, Xiong L, Yu X, Luo L, Cui K, Jin D, Xing Y, Zhang Q (2006). Genetic basis of drought resistance at reproductive stage in rice: separation of drought tolerance from drought avoidance. Genetics 172(2):1213-1228.

Zhu G, Ye N, Yang J, Peng X, Zhang J (2011). Regulation of expression of starch synthesis genes by ethylene and $\mathrm{ABA}$ in relation to the development of rice inferior and superior spikelets. Journal of Experimental Botany 62(11):3907-3916.

Zinolabedin TS, Hemmatollah P, Seyed A.M, Modarres S, Hamidreza B (2008). Study of water stress effects in different growth stages on yield and yield components of different rice (Oryza sativa L.) cultivars. Pakistan Journal of Biology Science 11:1303-130.

Zulkharnain WM, Ismail MR, Ashrafuzzaman M, Saud HM, Haroun IC (2009). Growth, physiological and biochemical responses of Malaysia rice cultivar to water stress. Pertanika Journal of Tropical Agricultural Science 32(2):323-333. 